\title{
Phylogenetic relationships amongst the saltwater members of the genus Bacteriovorax using rpo $B$ sequences and reclassification of Bacteriovorax stolpii as Bacteriolyticum stolpii gen. nov., comb. nov.
}

\author{
Correspondence \\ Silvia A. Piñeiro \\ spineiro@som.umaryland.edu
}

\author{
Silvia A. Piñeiro, ${ }^{1}$ Henry N. Williams ${ }^{2}$ and O. Colin Stine ${ }^{3}$ \\ 1Department of Medical and Research Technology, School of Medicine, University of Maryland, \\ Allied Health Building, 100 Penn Street, Baltimore, MD 21201, USA \\ ${ }^{2}$ Environmental Sciences Institute, Florida A\&M University, 1515 M. L. King, Jr Blvd., Tallahassee, \\ FL 32307, USA \\ ${ }^{3}$ Department of Epidemiology and Preventative Medicine, School of Medicine, University of \\ Maryland, 10 South Pine Street, Baltimore, MD 21201, USA
}

\section{INTRODUCTION}

Members of the genera Bdellovibrio and Bacteriovorax and similar organisms are obligate predatory bacteria that prey on other Gram-negative bacteria and can be isolated from many environmental sources (Stolp, 1968). They have a unique life cycle in which they have an extracellular attack phase followed by penetration into the periplasm of a host cell. In the periplasm, they undergo filamentous growth

Abbreviation: rpoB, $\beta$-subunit of RNA polymerase.

The GenBank/EMBL/DDBJ accession numbers for the rpoB gene sequences determined in this study are EF536750-EF536823 and EU240892-EU240893. and divide into several daughter cells that lyse the host cell to enter the extracellular attack phase (Ruby, 1991).

The genus Bacteriovorax was proposed with the reclassification of Bdellovibrio stolpii and Bdellovibrio starrii as members of the genus (Baer et al., 2000). Subsequently, the saltwater isolates Bacteriovorax marinus and Bacteriovorax litoralis were placed into the genus based on $16 \mathrm{~S}$ rRNA gene sequence analysis, DNA $\mathrm{G}+\mathrm{C}$ ratio, DNA-DNA hybridization and salinity experiments that differentiated them from Bdellovibrio spp. (Baer et al., 2004) and the freshwater Bacteriovorax strains, Bacteriovorax stolpii and Bacteriovorax starrii (subsequently renamed Peredibacter starrii by Davidov \& Jurkevitch, 2004). Delineation of 
species within the saltwater members of the genus Bacteriovorax is not yet resolved. Identification and classification of these micro-organisms are difficult because of the general absence of morphological or physiological features that can be tested in the presence of the prey cells. A number of attempts to set up reliable identification schemes based on phenotypic characterization or prey susceptibility, as well as initial molecular characterization, have been reported in previous studies (Seidler et al., 1969; Taylor et al., 1974; Marbach et al., 1975; Sutton \& Besant, 1994; Pineiro et al., 2004).

The $r p o B$ gene, which encodes the $\beta$-subunit of RNA polymerase, has been shown to be a useful and more discriminating alternative to the 16S rRNA gene for inferring phylogenetic relationships (Case et al., 2007). It has previously been demonstrated to be a suitable target on which to base species identification for the genera Staphylococcus (Drancourt \& Raoult, 2002), Mycoplasma (Kim et al., 2003), Bacillus (De Clerck \& De Vos, 2004) and Acinetobacter (La Scola et al., 2006).

In the case of the saltwater members of the family Bacteriovoracaceae, previous phylogenetic analysis based on 16S rRNA genes of isolates from various locations worldwide has revealed eight distinct phylogenetic clusters, along with three outlier isolates, based on $\geqslant 96.5 \%$ gene sequence similarity (Pineiro et al., 2007). In order to better define the phylogeny of the genus Bacteriovorax, 74 saltwater isolates, representatives of the 16S rRNA gene clusters and three outlier isolates, were selected, their $r p o B$ genes were sequenced and a phylogenetic tree was constructed. The $r p o B$ gene sequences from two freshwater isolates, Bacteriovorax stolpii and Peredibacter starrii (Baer et al., 2000), were included. The objective of this study was to demonstrate that phylogenetic analysis based on the rpoB gene from Bacteriovorax environmental isolates was consistent with and more discriminatory than the phylogenetic clustering obtained using $16 \mathrm{~S}$ rRNA genes. Finally, the reclassification of Bacteriovorax stolpii as Bacteriolyticum stolpii gen. nov., comb. nov. is proposed based on the extensive diversity between the saltwater members of the genus Bacteriovorax and the isolates derived from freshwater and soil.

\section{METHODS}

Bacterial strains and DNA processing. Seventy-four saltwater Bacteriovorax isolates were obtained from environmental samples collected in various countries as previously described (Pineiro et al., 2007). The freshwater/soil strains Bacteriovorax stolpii and Peredibacter starrii, donated by Dr E. Jurkevitch, were also included in the study. Lytic plaques of each isolate were obtained using a double overlay method with prey Vibrio parahaemolyticus, as described previously (Schoeffield \& Williams, 1990). Bacteriovorax stolpii and P. starrii were maintained as described by Baer et al. (2000). Prey cells were removed by filtration and DNA was extracted from the Bacteriovorax cells using a Qiagen kit according to the manufacturer's specifications. The DNA samples utilized were the same as those previously used for sequencing the 16S rRNA genes from these isolates (Pineiro et al., 2007).
Selection of $r p o B$ primers. Primers were designed based on aligned rpoB sequences from a spirochaete, Leptospira interrogans (GenBank accession no. AE010300); two gammaproteobacteria, Yersinia pestis (AL590842) and Salmonella enterica (AL627279); one alphaproteobacterium, Silicibacter pomeroyi (CP000031), and four deltaproteobacteria, Geobacter sulfurreducens (AE017180), Desulfovibrio vulgaris (AE017285), Bdellovibrio bacteriovorus HD100 (BX842654) and the saltwater strain Bacteriovorax marinus $\mathrm{SJ}^{\mathrm{T}}$ (http://www.sanger.ac.uk/ Projects/B_marinus/). The primers were selected in two highly conserved regions flanking a variable region of the $r p o B$ gene based on an analysis of variable regions using BioEdit (Hall, 2001). The primers $r p o B \mathrm{~F}, 5^{\prime}$-CCTAATGGGATCGAACATG-3', and rpoBR, 5'GATAA CACCTTTGT TACCGTG-3', resulted in a $1242 \mathrm{bp}$ fragment and were used for both amplification and sequencing.

DNA sequencing and phylogenetic analysis. The $r p o B$ gene fragments were obtained using Taq Ready to Go PCR beads (Amersham Biosciences) according to manufacturer's specifications. All the PCR mixtures were subjected to an initial denaturation at $94{ }^{\circ} \mathrm{C}$ for $2 \mathrm{~min}$ and to 35 cycles of denaturation for $30 \mathrm{~s}$ at $94{ }^{\circ} \mathrm{C}$, $30 \mathrm{~s}$ at $50{ }^{\circ} \mathrm{C}$ for annealing and $10 \mathrm{~s}$ at $72{ }^{\circ} \mathrm{C}$ for extension, followed by $7 \mathrm{~min}$ at $72{ }^{\circ} \mathrm{C}$ for a final extension. PCR products were purified with Multiscreen PCR plates (Millipore) and sequenced using the BigDye Terminator v3.1 cycle sequencing kit (Applied Biosystems). The resulting fragments were separated and recorded in an $\mathrm{ABI}$ 3730xl automatic sequencer (Applied Biosystems). All PCR products were sequenced in both directions. Raw sequence data were compiled using the Phred/Phrap/Consed package (Ewing \& Green, 1998; Ewing et al., 1998; Gordon et al., 1998). The low quality bases from the ends were removed and the resulting sequences were aligned using CLUSTAL_X v1.8 (Jeanmougin et al., 1998). Chimeras were tested for by using the sequences aligned against those of Vibrio parahaemolyticus. Analysis of the aligned sequences was performed using the distance matrix, neighbour-joining and bootstrapping algorithms as implemented in PAUP (Swofford, 2002; PAUP version 3.1, Sinauer Associates). Trees were constructed using maximum-parsimony and maximum-distance methods and the uncorrected ' $p$ ' model for substitution (Fig. 1). Branch supporting values were evaluated with 1000 bootstrap replications.

\section{RESULTS AND DISCUSSION}

The primers chosen for $r p o B$ gene amplification from the Bacteriovorax isolates included a region that began and ended at bases 2073 and 3315, respectively, of the Bacteriovorax marinus $\mathrm{SJ}^{\mathrm{T}}$ rpoB gene (http://www.sanger.ac.uk/Projects/ B_marinus/). The $r p o B$ gene sequences were obtained from 74 saltwater and one freshwater Bacteriovorax isolate, aligned and analysed using a neighbour-joining algorithm. The phylogenetic tree was constructed using G. sulfurreducens, another member of the class Deltaproteobacteria, as the outgroup as previously described for $16 \mathrm{~S}$ rRNA gene analysis (Pineiro et al., 2007). The phylogenetic tree analysis based on $r p o B$ gene sequences showed 15 groups, labelled $\mathrm{A}$ to $\mathrm{O}$, and numerous singletons (Fig. 1). The groups were defined by bootstrapping of 1000 replicates. If groups were defined as those isolates that grouped together with bootstrap value of $\geqslant 96 \%$, then 15 groups were identified. Alternatively, if the groups were assigned by sequence similarity of $\geqslant 96 \%$ between members of the same group, then only 9 groups could be found. Groups C, D and E, G and H, and K and L coalesced when classified by similarity, since the isolates had 


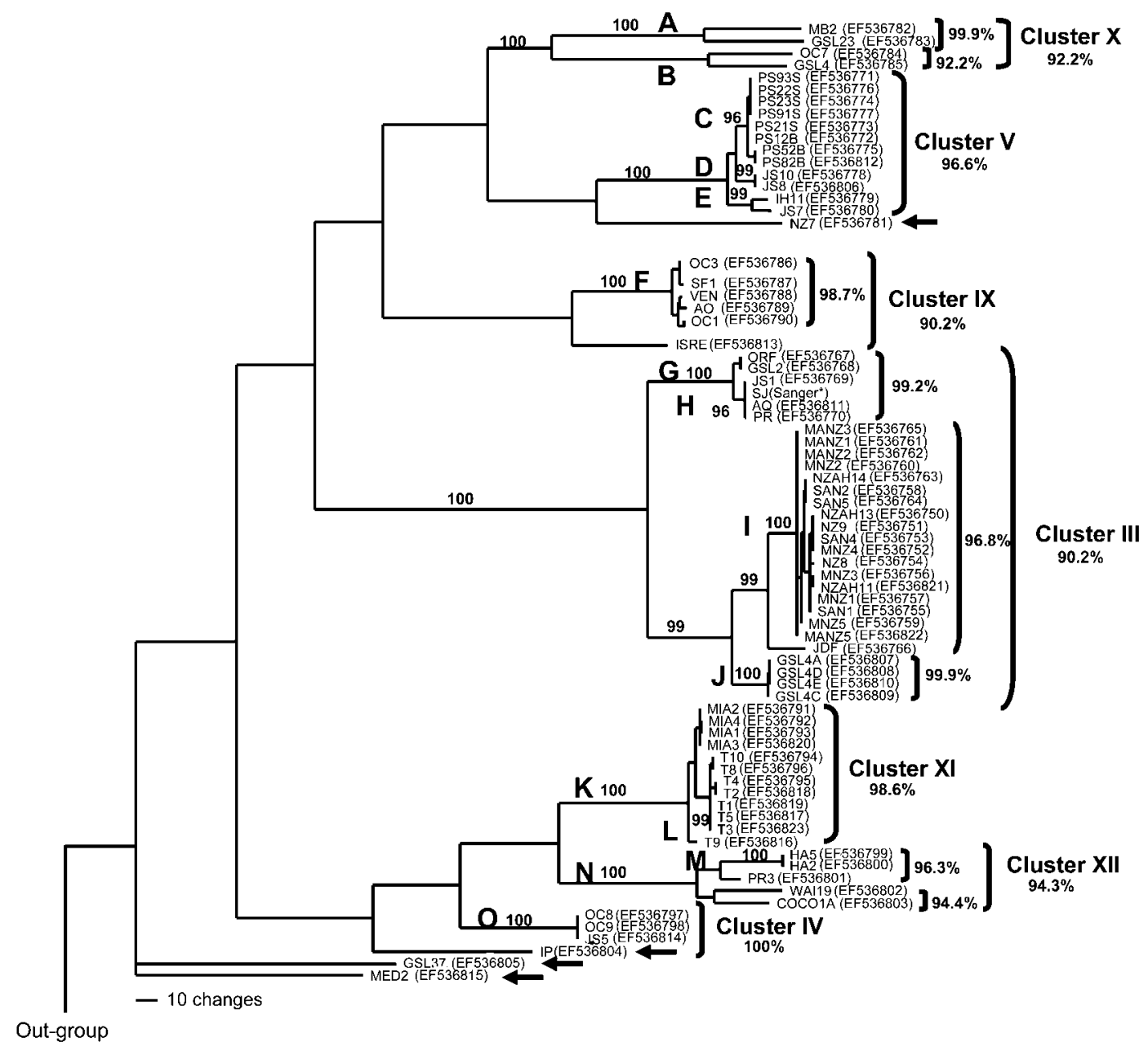

Fig. 1. Phylogenetic tree for Bacteriovorax isolates based on $r p o B$ gene sequences. Percentages with cluster designations are $r p o B$ gene sequence similarity. The numbers on the branches correspond to bootstrap values based on 1000 replicates. Groups that bootstrap together $\geqslant 96 \%$ of the time based on their rpoB gene sequence are represented by letters. Clusters based on 16S rRNA gene sequence analysis are numbered consistently with previously published works (Davidov \& Jurkevitch, 2004; Pineiro et al., 2007). GenBank accession numbers are given in parentheses. Sanger*: http://www.sanger.ac.uk/Projects/ B_marinus/. Bar, 10 nucleotide changes.

gene sequence similarities of $\geqslant 96 \%$. Less stringent conditions will produce larger groups, but the groups need to be based on data from additional loci.

The $r p o B$ gene sequences of the saltwater Bacteriovorax isolates were compared with those of the freshwater isolates Bacteriovorax stolpii and Peredibacter starrii. The genetic distances to Bacteriovorax stolpii ranged from 19 to $24 \%$ nucleotide differences and for $P$. starrii from 24 to $27 \%$. These distances were comparable to those within the saltwater Bacteriovorax isolates (21 to $24 \%$ ) and were less than to Bdellovibrio bacteriovorus ( 37 to $41 \%$ ) and to other bacteria ( 43 to $51 \%$ ). While these distances clearly indicate that the various taxa are distinct, the distance metric is unlikely to be accurate because of the high likelihood of multiple substitutions at a single site.
A comparison of the $r p o B$ sequences of the saltwater Bacteriovorax isolates with those from genera of other classes of the phylum Proteobacteria revealed insertion/ deletion mutations (Fig. 2). In this paper, insertion/ deletions are referred to relative to Bacteriovorax marinus $\mathrm{SJ}^{\mathrm{T}}$ and no inference is intended regarding the phylogeny of these events. When other bacterial species (belonging to various classes of the phylum Proteobacteria) were examined, a 6 bp insertion was found starting at base 2363 of Bacteriovorax marinus $\mathrm{SJ}^{\mathrm{T}}$ in the species $G$. sulfurreducens, Salmonella enterica and $Y$. pestis, while a 3 base insertion was found in Silicibacter pomeroyi, Bdellovibrio bacteriovorus and D. vulgaris (Fig. 2a). A second insertion/deletion occurrence started at nucleotide position 3052 of the Bacteriovorax marinus $\mathrm{SJ}^{\mathrm{T}}$ sequence. Silicibacter pomeroyi was found to have a 15 bp deletion in 


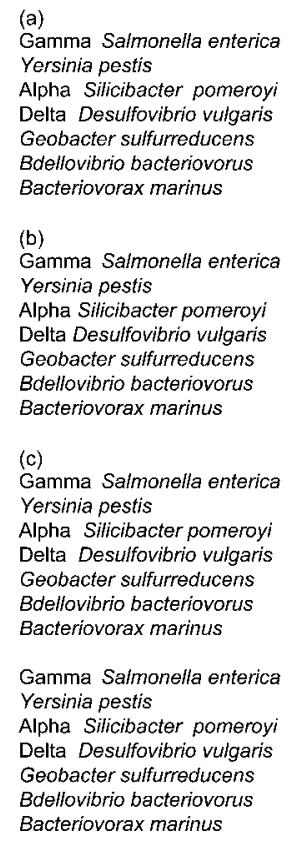

TGCATCCCGTATCGTTATCAAAGTTAACGAAGACGAGATGTACCCGGGTGAAGCAGGTAT TGCATCCCGTATCGTTATTAAAGTTAACGAAGATGAGATGCACCCAGGCGAAGCCGGCAT CGCGCAGCGGATCGTGATTCG---CGCCACCGAGGATCTGGAACTGGGCGATGCGGGCGT CGCCACGCGCATCATCGTCAG---CTACGAGAACGGGCTCTACCCCGATCGTGGCGGCGT TOCCTCTCGCATCOTTGTCARAATCGACGAGGACGRGTTCGATGRAACCGGCACCGGTGT TGCTTCCCGLATCGTTATCCGTCGTTTC---GCCAAAGGCGGCGAGCTGGGTGCGAACGT TTCAAACAGAATCGTTATTCAA----AGAGATAAATTTAAAGATGGTGAATCTGGTGT $* \quad * * * * * 2362$

GAAC----GAGT-_-_GACGAGC------TGGCGAT-----CTTGGACCGCAACATCTATGCGCGTCTGAAGTCGCTGATCCTGGGC CACGTCCGTGCCCTTGGCGATGCCCTGCGCGACCGTCTCGCCGATACCCTGGTGGGCAAGCAGATTGCCGTC GAGATCCGCATCATCCGCAATTCCGCCGTGGGCAAGCTCAAGAAGCTCCTCGTCGGCAAGTCCGCTGCGGTC GAGCAGAACGTTATCAAAAATAACGCTATCTCCAAACTTCGTGACATCCTGGTGGGTAAAATCACTACAGGC GAAATTAAAGCAATTCAAACTTCAGCAATCCTAAAGATTGCAGARATGCTTAATGGTGCARARATTACTGAC $305 \overline{2}$ $310 \overline{7}$

GCCTGTTTAGCCGTA---TCCGTGCGGTGTTGGTGTCCGGCGGCGTTGAAGCTGAGAAGGCTTGTT TGCACGTA---TCCACGCGGTTCTGGTTTCTGGTGGCATCGAAGCTGAGAAGCCGCGGTCAAGGGCC----CCAAGGGC--ATCAAGCCGGGTTCCGAGATCACCGAAGAGC TGCCCGGCAAGCGCAAGGGCGAGGTGCTGGCTGAAGCTGGTGCCCCCATGACCCGCGAAC TGGAGGACAAGAGCG---GCCGGACCGTCATCGCCAAGGGTGCCGCCATIACCGAAGAG TTCTGAATGAAGACGGTTCTCACAAGTTGTTCAACA AGGTCAGGAAATCACAGAGGCOG TCGTTTCTGAAGATGGTTCAGCAGAACTACTTTCTAAGGGAACTGAGATTACTGGTGAGA 3135

--CTCGACAAACTGCCGCGCGACCGC-TGGC--TGGAACTCGGTCTGACCGACGAAGAGA

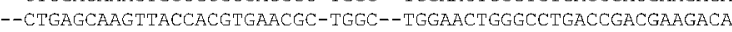
TGCTGGAAACCCTGACCCGCGGTCAG-TGGT--GGATGCTGGCTCTGGAAGGTGAGCAGG TTCTCGACGCCCTGCCCGTCAAGCGGCTGGC--AGGT-CTG--TTCAAGAGCCGTG-AGG CCCTTGACGCGATCCCGCTCGATCGTTGGGACGAGATTTCCGTGTCCGGCGAGGCGGGG ATCTAGAGACAGTTCCATTCGAATTGTTGA--CTACATCCCTCTTGAGC----AAGACC ATCTAGAGACAGTTCCATTCGAATTGTTGA--CTACATCCCTCTTGAGC----AAGACO TTCTTGCTTCAATCCCATTTGAGCTAATTGG
$*$ *

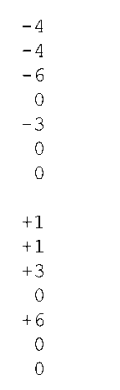

Fig. 2. CLUSTAL_X $\mathrm{v} 1.81$ multiple sequence alignment for $r p o B$ numbering based on Bacteriovorax marinus $\mathrm{S} \mathrm{J}^{\top}$ (http:// www.sanger.ac.uk/Projects/B_marinus/). Asterisks identify invariant nucleotides.

this region and the two gammaproteobacteria had $54 \mathrm{bp}$ deletions (Fig. 2b). A third region where insertion/deletion events were detected was around bases 3135 to 3239 of the Bacteriovorax marinus $\mathrm{SJ}^{\mathrm{T}}$ sequence. Through this region Bacteriovorax marinus, Bdellovibrio bacteriovorus and D. vulgaris had the same number of nucleotides, G. sulfurreducens had 3 more nucleotides, while Silicibacter pomeroyi, Salmonella enterica and $Y$. pestis had 3 fewer nucleotides (Fig. 2c). It is worth noting that all of the insertions/deletion events were multiples of three, consistent with the conservation of the reading frame so that a proper enzyme can be formed. These insertions/deletions did not separate phylogenetic groups within the Bacteriovorax isolates. The first separated Bacteriovorax isolates from the other members of the class Deltaproteobacteria, the second separated the deltaproteobacteria from the other subdivisions and the third separated out $G$. sulfurreducens from the other members of the class Deltaproteobacteria.

The phylogenetic groups based on $r p o B$ gene sequences were compared with the clusters based on $16 \mathrm{~S}$ rRNA gene sequences (Fig. 1). The 16S rRNA gene clusters III, IV, V, IX, X, XII, XIII were identified previously (Pineiro et al., 2007) and were composed of isolates with $\geqslant 96.5 \%$ gene sequence similarity. In general, there was very good agreement between the groups identified by $r p o B$ gene sequencing and the clusters identified by $16 \mathrm{~S}$ rRNA gene sequencing. Groups $\mathrm{C}, \mathrm{D}$ and $\mathrm{E}$, based on rpoB gene sequences, and cluster $\mathrm{V}$, based on $16 \mathrm{~S}$ rRNA gene sequences, had identical sets of isolates and contained only isolates from estuarine environments. Similarly, groups $\mathrm{K}$ and $\mathrm{L}$ and cluster XI had an identical set of isolates and were from tropical locations (Miami, FL, USA, and Trinidad, Cuba). The groups A and B, G, H and I, K and L, and $\mathrm{M}$ and $\mathrm{N}$, were most closely related to the other groups from the same 16S rRNA gene cluster (X, III, XI and XII). These groups may well represent smaller phylogenetic taxa within the clusters defined by 16S rRNA gene sequence analysis as is the case for the genus Prochlorococcus which has six ecotypes with 16S rRNA gene sequences that diverge by less than $3 \%$ (Johnson et al., 2006). The genus Salinispora has three species with $99 \%$ or greater similarity at the 16S rRNA gene locus (Jensen \& Mafnas, 2006) and Yersinia pestis has species defined both by biochemical tests and by multi-locus sequencing typing that cannot be distinguished by 16S rRNA gene sequences (Kotetishvili et al., 2005). These observations and the groups found within the identified clusters may indicate that the family Bacteriovoracaceae is even more diverse than shown in this study. However, before these taxonomic groups are elevated to recognized species, additional information will be required to meet the criteria set forth by the ad hoc Committee for the Re-evaluation of the Species Definition in Bacteriology (Stackebrandt et al., 2002) and others (Gurtler \& Mayall, 2001; Rosselló-Mora \& Amann, 2001).

Although insertion/deletion events are generally rare in $16 \mathrm{~S}$ rRNA genes, there were four locations where these events have occurred in the $16 \mathrm{~S}$ rRNA gene of the family 
Bacteriovoracaceae. Two events distinguish the predatory deltaproteobacteria. One, a single base insertion relative to the Escherichia coli sequence (AF233451) near E. coli nucleotide position 1113 (Fig. 3a), was found in all isolates from the families Bdellovibrionaceae and Bacteriovoracaceae. A second single base insertion was found in the family Bacteriovoracaceae near E. coli nucleotide position 436. In contrast, members of the family Bdellovibrionaceae had a 23 base insertion at this location (Fig. 3b). This genetic variance unambiguously separated these two families of predatory bacteria. The other two events subdivided the family Bacteriovoracaceae. The third location was near E. coli nucleotide position 164 where most saltwater members of the family Bacteriovoracaceae had a single base deletion, in contrast to the freshwater Bacteriovorax/Peredibacter lineage that had a 10 base deletion. The saltwater cluster XIII, including strain MED2, also had the larger deletion, consistent with the presence of strain MED2 as an outlier at the base of the $r p o B$ phylogenetic tree. The fourth location was between nucleotide positions 181 and 199 in the E. coli sequence. There were six distinct patterns within the family Bacteriovoracaceae and two more within the family Bdellovibrionaceae. The family Bdellovibrionaceae had three or five more bases than E. coli (Fig. 3d), consistent with the insertion in the 16S rRNA gene near nucleotide position 436 and the $r p o B$ difference near to nucleotide position 2363 of Bacteriovorax marinus $\mathrm{SJ}^{\mathrm{T}}$. These three observations all supported the separation of these two families. There were five distinct patterns within the family Bacteriovoracaceae (Fig. 3d). Three patterns were found in the saltwater clusters. 16S rRNA gene clusters V, IX and X had 16 more bases than the E. coli sequence, clusters III, IV, XI and XII had 17 bases more than E. coli, and cluster XIII containing MED2 had only four more bases. The freshwater isolates also showed three patterns, cluster VII containing $P$. starrii had nine more bases than the E. coli sequence, while cluster I containing Bacteriovorax stolpii and strain PNEcl had 14 and 15 more bases, respectively. These data confirm the division of cluster XIII away from the other saltwater isolates and the separation of the saltwater and freshwater isolates. The partitions are also consistent with the groupings seen using the $r p o B$ gene sequence. Clusters V, IX and X corresponded to rpoB groups A-F; clusters III, IV, XI and XII to groups $\mathrm{G}-\mathrm{O}$; and cluster XIII, containing MED2, was distinct. The distinctiveness of cluster XIII may explain why, despite repeated attempts, we were unable to obtain an $r p o B$

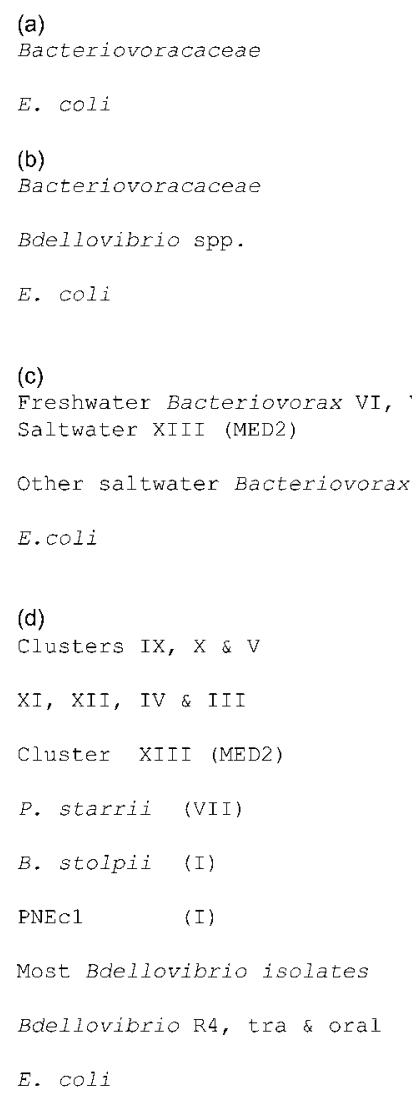

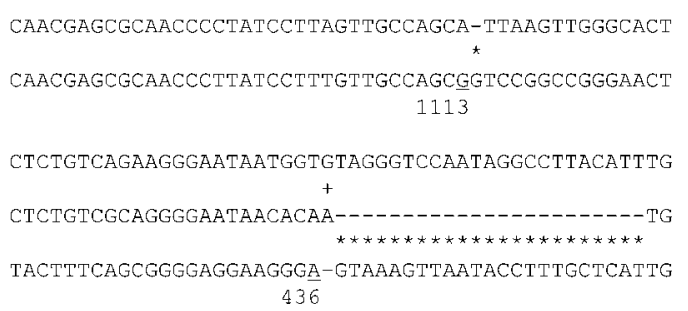

TAACCAGGAGAAATCCTGGCTAATACCGCATAAG----------TAAG TAACTAATCGAAAGATTAGCTAATACCGCATAAG-ACCACGGGAACTG

TAACTACTGGAAACGGTAGCTAATACCGCATAACGTCGCAAGACCAAA 164

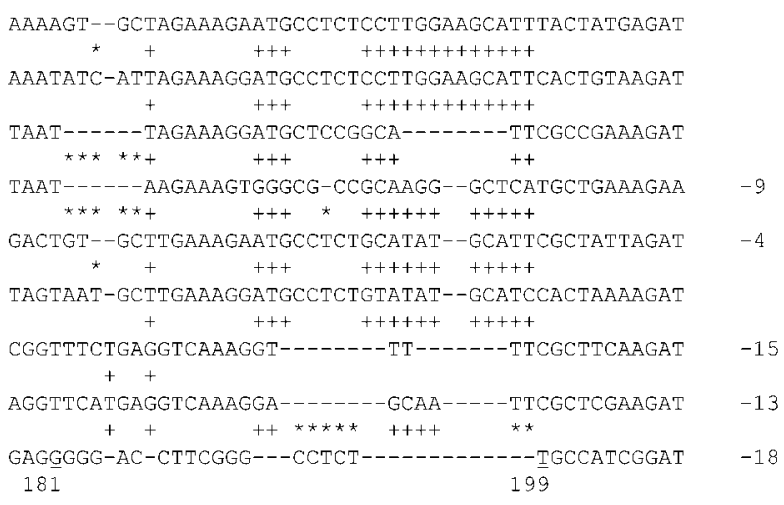

Fig. 3. CLUSTAL_X v1.81 multiple sequence alignment for $16 \mathrm{~S}$ rRNA genes. All asterisks represent deleted bases and all plus signs represent inserted bases relative to the E. coli 16S rRNA gene (GenBank accession no. AF233451). The underlined nucleotides in the $E$. coli sequence are associated with the number underneath. 
sequence from the other isolate in the cluster, GSL4B. The isolate GSL37 was an outlier located near the base of the rpoB gene tree and was ambiguously placed on the basis of $16 \mathrm{~S}$ rRNA gene sequence alone. The pattern for insertions/ deletions in the 16S rRNA gene for this isolate was the same as that of isolates in clusters V, IX and X. Finally, the outlier isolates previously revealed by $16 \mathrm{~S}$ rRNA gene sequence analysis, strains IP and NZ7, were consistent with the phylogenetic analysis using the $r p o B$ gene.

In conclusion, we found that the $r p o B$ nucleotide sequences were more variable than the $16 \mathrm{~S}$ rRNA gene sequences. The variation was consistent with that observed in sequence and insertions/deletions in the 16S rRNA locus. Some of the $16 \mathrm{~S}$ rRNA gene clusters were subdivided by the greater nucleotide variation in the $r p o B$ gene, possibly indicating that more narrowly delineated phylogenetic groups may be defined among the saltwater isolates of the genus Bacteriovorax. The formal establishment of defined taxonomic groups at the species level will require information from additional loci.

The wide dissimilarities in $16 \mathrm{~S}$ rRNA gene sequence analysis between the family Bdellovibrionaceae and the newly described family Bacteriovoracaceae served as a basis for the construction of the genus Bacteriovorax (Baer et al., 2000) and, even more recently, the reclassification of Peredibacter starrii was proposed (Davidov \& Jurkevitch, 2004). The differences in 16S rRNA and $r p o B$ gene sequences between the genera Bdellovibrio, Bacteriovorax and Peredibacter are large enough to place each in its own family. Our additional data give rise to additional taxonomic categories. The reclassification of Bacteriovorax stolpii as Bacteriolyticum stolpii gen. nov., comb. nov. is proposed based on the extensive diversity between the saltwater members of the genus Bacteriovorax and the freshwater/soil isolates.

\section{Description of Bacteriolyticum gen. nov.}

Bacteriolyticum (Bac.ter'io.lyt.i.cum. Gr. n. bakterion staff, cane and in biology, a bacterium; Gr. adj. lutikos able to loosen, able to dissolve; N.L. neut. n. Bacteriolyticum a dissolver of bacteria).

This genus consists of Gram-negative bacteria that prey upon other Gram-negative bacteria to complete a biphasic life cycle. The morphological description of the genus is the same as that of the type and only described species, Bacteriolyticum stolpii.

\section{Description of Bacteriolyticum stolpii comb. nov.}

Bacteriolyticum stolpii (stol'pi.i. N.L. masc. gen. n. stolpii of Stolp, named after the American microbiologist Stolp).

Basonym: Bdellovibrio stolpii Seidler et al. 1972 (Approved Lists 1980).

Other homotypic synonym: Bacteriovorax stolpii Baer et al. 2000.
The description of the species is based on those of Baer et al. (2000) and Seidler et al. (1972). The species is separate from the genera Peredibacter and Bacteriovorax as Bacteriovorax stolpii has very low levels of DNA-DNA relatedness, $4 \%$ and $7.7 \%$ to $P$. starrii and Bacteriovorax marinus $\mathrm{SJ}^{\mathrm{T}}$, respectively (Baer et al., 2004). 16S rRNA gene sequence analysis shows the similarity between the freshwater/soil isolate Bacteriovorax stolpii and the saltwater species Bacteriovorax marinus $\mathrm{SJ}^{\mathrm{T}}$ to be $89 \%$. The maximum 16S rRNA gene sequence similarity to any saltwater member of the genus Bacteriovorax is $90.8 \%$ and ranges down to $81 \%$ (Pineiro et al., 2007).

The type strain is $\mathrm{Uki2}^{\mathrm{T}} \quad\left(=\mathrm{ATCC} \quad 27052^{\mathrm{T}}=\mathrm{DSM}\right.$ $12778^{\mathrm{T}}=$ DSM $50722^{\mathrm{T}}$ ).

\section{Description of Peredibacteraceae fam. nov.}

Peredibacteraceae (Pe.re.di.bac'ter.a.ce.ae. N.L. fem. n. Peredibacter the genus of Gram-negative, aerobic, predatory bacteria is the type genus of the family; suffix aceae denoting family; N.L. fem. pl. n. Peredibacteraceae the Peredibacter family).

The description of the family Peredibacteraceae is based on the description of the genus Peredibacter (Davidov \& Jurkevitch, 2004) and the data from this study. This family is composed of Gram-negative, vibriod shaped bacteria about $0.5 \mu \mathrm{m}$ in length. Obligate predators of other Gramnegative bacteria. They exhibit a biphasic life cycle consisting of a motile attack phase and a phase that dwells in the periplasm of prey bacteria. They are a monophyletic offshoot of the family Bacteriovoracaceae. The only recognized species are found in freshwater and soil environments. The DNA $\mathrm{G}+\mathrm{C}$ contents of the saltwater Bacteriovorax strains $\mathrm{SJ}^{\mathrm{T}}, \mathrm{AQ}$ and JS5 are in the range of 37.7-38.3 mol\% (Baer et al., 2004) compared with the higher values of $43.5 \mathrm{~mol} \%$ for Peredibacter starrii and $41.8 \mathrm{~mol} \%$ for Bacteriolyticum stolpii [previously Bacteriovorax stolpii (Seidler et al., 1972)]. These species grow on prey in freshwater. The two species have distinctive numbers of nucleotides between $E$. coli bases 181 and 199 that differ from both the families Bacteriovoracaceae and Bdellovibrionaceae. The type genus is Peredibacter (Davidov \& Jurkevitch, 2004 who revised Seidler et al., 1972).

\section{ACKNOWLEDGEMENTS}

This work has been supported by NSF grant OCE-0455276. Special thanks to Dr Guili Zheng and Mrs Susan Steyert for their contributions.

\section{REFERENCES}

Baer, M. L., Ravel, J., Chun, J., Hill, R. T. \& Williams, H. N. (2000). A proposal for the reclassification of Bdellovibrio stolpii and Bdellovibrio starrii into a new genus, Bacteriovorax gen. nov. as Bacteriovorax stolpii comb. nov. and Bacteriovorax starrii comb. nov., respectively. Int J Syst Evol Microbiol 50, 219-224. 
Baer, M. L., Ravel, J., Pineiro, S. A., Guether-Borg, D. \& Williams, H. N. (2004). Reclassification of salt-water Bdellovibrio sp. as Bacteriovorax marinus sp. nov. and Bacteriovorax litoralis sp. nov. Int J Syst Evol Microbiol 54, 1011-1016.

Case, R. J., Boucher, Y., Dahllof, I., Holmstrom, C., Doolittle, W. F. \& Kjelleberg, S. (2007). Use of $16 \mathrm{~S}$ rRNA and $r p o B$ genes as molecular markers for microbial ecology studies. Appl Environ Microbiol 73, 278-288.

Davidov, Y. \& Jurkevitch, E. (2004). Diversity and evolution of Bdellovibrio-and-like organisms (BALOs), reclassification of Bacteriovorax starrii as Peredibacter starrii gen. nov., comb. nov., and description of the Bacteriovorax-Peredibacter clade as Bacteriovoracaceae fam. nov. Int J Syst Evol Microbiol 54, 1439-1452.

De Clerck, E. \& De Vos, P. (2004). Genotypic diversity among Bacillus licheniformis strains from various sources. FEMS Microbiol Lett 231, 91-98.

Drancourt, M. \& Raoult, D. (2002). $r p o B$ gene sequence-based identification of Staphylococcus species. J Clin Microbiol 40, 1333-1338.

Ewing, B. \& Green, P. (1998). Base-calling of automated sequencer traces using phred. II. Error probabilities. Genome Res 8, 186-194.

Ewing, B., Hillier, L., Wendl, M. C. \& Green, P. (1998). Base-calling of automated sequencer traces using phred. I. Accuracy assessment. Genome Res 8, 175-185.

Gordon, D., Abajian, C. \& Green, P. (1998). Consed: a graphical tool for sequence finishing. Genome Res 8, 195-202.

Gurtler, V. \& Mayall, B. C. (2001). Genomic approaches to typing, taxonomy and evolution of bacterial isolates. Int J Syst Evol Microbiol 51, 3-16.

Hall, T. (2001). BioEdit Biological sequence alignment editor. Carlsbad, CA: Ibis Biosciences.

Jeanmougin, F., Thompson, J. D., Gouy, M., Higgins, D. G. \& Gibson, T. J. (1998). Multiple sequence alignment with CLUSTAL_X. Trends Biochem Sci 23, 403-405.

Jensen, P. R. \& Mafnas, C. (2006). Biogeography of the marine actinomycete Salinispora. Environ Microbiol 8, 1881-1888.

Johnson, Z. I., Zinser, E. R., Coe, A., McNulty, N. P., Woodward, E. M. \& Chisholm, S. W. (2006). Niche partitioning among Prochlorococcus ecotypes along ocean-scale environmental gradients. Science 311, 1737-1740.

Kim, K. S., Ko, K. S., Chang, M. W., Hahn, T. W., Hong, S. K. \& Kook, Y. H. (2003). Use of $r p o B$ sequences for phylogenetic study of Mycoplasma species. FEMS Microbiol Lett 226, 299-305.

Kotetishvili, M., Kreger, A., Wauters, G., Morris, J. G., Jr, Sulakvelidze, A. \& Stine, O. C. (2005). Multilocus sequence typing for studying genetic relationships among Yersinia species. J Clin Microbiol 43, 2674-2684.

La Scola, B., Bui, L. T., Baranton, G., Khamis, A. \& Raoult, D. (2006). Partial $r p o B$ gene sequencing for identification of Leptospira species. FEMS Microbiol Lett 263, 142-147.

Marbach, A., Varon, M. \& Shilo, M. (1975). Properties of marine Bdellovibrios. Microb Ecol 2, 284-295.

Pineiro, S. A., Sahaniuk, G. E., Romberg, E. \& Williams, H. N. (2004). Predation pattern and phylogenetic analysis of Bdellovibrionaceae from the Great Salt Lake, Utah. Curr Microbiol 48, 113-117.

Pineiro, S. A., Stine, O. C., Chauhan, A., Steyert, S. R., Smith, R. \& Williams, H. N. (2007). Global survey of diversity among environmental saltwater Bacteriovoracaceae. Environ Microbiol 9, 2441-2450.

Rosselló-Mora, R. \& Amann, R. (2001). The species concept for prokaryotes. FEMS Microbiol Rev 25, 39-67.

Ruby, E. G. (1991). The genus Bdellovibrio. In The Prokaryotes, pp. 3000-3015. Edited by A. Balows, H. G. Trüper, M. Dworkin, W. Harder, \& K. H. Schleifer. Springer-Verlag Press.

Schoeffield, A. J. \& Williams, H. N. (1990). Efficiencies of recovery of Bdellovibrios from brackish-water environments by using various bacterial species as prey. Appl Environ Microbiol 56, 230-236.

Seidler, R. J., Starr, M. P. \& Mandel, M. (1969). Deoxyribonucleic acid characterization of Bdellovibrios. J Bacteriol 100, 786-790.

Seidler, R. J., Mandel, M. \& Baptist, J. N. (1972). Molecular heterogeneity of the Bdellovibrios: evidence of two new species. J Bacteriol 109, 209-217.

Stackebrandt, E., Frederiksen, W., Garrity, G. M., Grimont, P. A., Kämpfer, P., Maiden, M. C., Nesme, X., Rosselló-Mora, R., Swings, J. $\&$ other authors (2002). Report of the ad hoc committee for the reevaluation of the species definition in bacteriology. Int J Syst Evol Microbiol 52, 1043-1047.

Stolp, H. (1968). Bdellovibrio bacteriovorus-a predatory bacterial parasite. Naturwissenschaften 55, 57-63 (in German).

Sutton, D. \& Besant, P. (1994). Ecology and characteristics of bdellovibrios from three tropical marine habitats. Mar Biol 119, 313-320.

Swofford, D. L. (2002). PAUP*: Phylogenetic analysis using parsimony (and other methods), version 4. Sunderland, MA: Sinauer Associates.

Taylor, V. I., Baumann, P., Reichelt, J. L. \& Allen, R. D. (1974). Isolation, enumeration, and host range of marine Bdellovibrios. Arch Microbiol 98, 101-114. 